\title{
Análise de parâmetros físicos, químicos e biológicos necessários à qualidade de adubo orgânico oriundo de processo de compostagem realizado na Universidade Estadual da Paraíba, PB
}

O presente trabalho é resultado de um projeto de extensão universitária, realizado na Escola Municipal Padre Cornélio de Boer, em Campina Grande - PB, junto a 66 estudantes de turmas do pré-escolar II, 2ㅇ, 으 e 5ㅇa ano do Ensino Fundamental I. Os resíduos sólidos orgânicos gerados na escola foram coletados, triados, misturados a folhas, pesados e colocados em três composteiras de concreto, dispostas no sistema de tratamento descentralizado de resíduos orgânicos (SITRADERO), localizado no anexo do laboratório do Grupo de Extensão e Pesquisa em Gestão e Educação Ambiental, do Departamento de Biologia (GGEA/DB/UEPB). A partir de então, foi realizado o monitoramento (por um período de 104 dias), de diversos parâmetros dentre eles: analises diárias (temperatura), semanais (sólidos totais, umidade, aeração, pH, mesoinvertebrados e carbono orgânico), início e final do experimento (ovos de helmintos) e apenas ao termino processo de compostagem (potássio, fósforo e nitrogênio), para caracterizar a sanitização do composto (adubo orgânico) em formação. Como resultado do monitoramento do sistema, observou-se que os valores obtidos para quase todas as análises estavam de acordo com a Instrução Normativa no 25 , de 23 de julho de 2009 do Ministério da Agricultura, Pecuária e Abastecimento para fertilizantes orgânicos, os valores finais obtidos foram: pH $(8,05)$, SVT $(36,18 \%)$, COT $(20 \%)$, Umidade $(32 \%)$, Ovos de helmintos $(0,0$ ovos/gst), Nitrogênio total $(1,3)$ e Fósforo $(4,2)$, os valores obtidos para potássio $(0,80)$ não atinge os valores sugeridos pela Instrução Normativa $n=25$. Ao final do período de monitoramento do sistema de compostagem, 0 mesmo foi desmontado, pois todas as análises físicas, químicas e biológicas indicavam estabilização. Passou-se então à realização do peneiramento e à classificação do composto. A retirada do composto das composteiras foi feita com auxílio de bacias e pás, seguido do peneiramento em peneiras de malha $4 \mathrm{~mm}$ e $2 \mathrm{~mm}$ para classificação. 0 composto orgânico obtido recebeu três classes: rejeito, farelo e pó de acordo com a Instrução Normativa do Ministério da Agricultura, Pecuária e Abastecimento o 25, de 23 de julho de 2009.

Palavras-chave: Compostagem; Matéria orgânica; Sanitização.

\section{Analysis of physical, chemical and biological parameters necessary for the quality of organic fertilizer from the composting process carried out at the State University of Paraíba, PB}

\begin{abstract}
The present work is the result of a university extension project, carried out at the Padre Cornelio de Boer Municipal School, in Campina Grande - PB, with 66 students from pre-school classes II, 2nd, 3rd and 5th year of Elementary School I. The organic solid waste was sorted, mixed with leaves, weighed and, in three concrete composters, disposed in the decentralized solid waste treatment system (SITRADERO), located in the annex of the laboratory of the Extension and Research Group in Management and Education of the Department of Biology (GGEA/DB/UEPB). From then on, monitoring (for a period of 104 days) was carried out of several parameters, including daily (temperature), weekly (total solids, humidity, aeration, pH, mesoinvertebrates and organic carbon) analyzes, beginning and end of the experiment (helminth eggs) and only at the end of the composting process (potassium, phosphorus and nitrogen), to characterize the sanitization of the compost (organic fertilizer) in formation. As a result of the system monitoring, it was observed that the values obtained for almost all analyzes were in accordance with Normative Instruction No. 25, of July 23, 2009, from the Ministry of Agriculture, Livestock and Supply for single fertilizers, the final values were removed: $\mathrm{pH}(8.05)$, SVT (36.18\%), TOC (20\%), Humidity (32\%), Helminth eggs ( 0.0 eggs/gst), Total nitrogen (1.3) and Phosphorus (4.2), the values obtained for potassium (0.80) do not reach the values suggested by Normative Instruction No. 25. At the end of the monitoring period of the composting system, it was disassembled, since all physical analyzes, products and biologicals indicated stabilization. Then, the screening and classification of the compost was carried out. The compost removal was done with the aid of basins and shovels, followed by sieving in $4 \mathrm{~mm}$ and $2 \mathrm{~mm}$ mesh sieves for classification. The compound composed of three classes: tailings, bran and powder according to the Normative Instruction of the Ministry of Agriculture, Livestock and Supply no. 25, of July 23, 2009.
\end{abstract}

Keywords: Composting; Organic matter; Sanitization.

Topic: Desenvolvimento, Sustentabilidade e Meio Ambiente

Reviewed anonymously in the process of blind peer.

Maria José Silva (iD

Centro Universitário Maurício de Nassau, Brasil

http://orcid.org/0000-0001-9268-4224

mariajsilva1397@gmail.com

Adrianne Teixeira Barros (1D)

Universidade Estadual da Paraíba, Brasil

http://lattes.cnpq.br/3228203365280543

http://orcid.org/0000-0002-7393-642X

adriannebarros@yahoo.com.br

Érick Jardel de Araújo Silva (iD

Universidade Estadual da Paraíba, Brasil

http://lattes.cnpq.br/3513611128786785

http://orcid.org/0000-0002-6866-5098

erickaraujoxcv@gmail.com

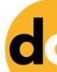

DOI: 10.6008/CBPC2179-6858.2021.007.0034
Received: 02/07/2021

Approved: 28/07/2021

\author{
Lívia Duarte Marinho de Melo (iD \\ Universidade Estadual da Paraíba, Brasil \\ http://lattes.cnpq.br/3513611128786785 \\ http://orcid.org/0000-0002-6866-5098 \\ liviaduartemarinho@gmail.com \\ Fernando Luiz Barbosa Farias (it) \\ Universidade Estadual da Paraíba, Brasil \\ http://lattes.cnpq.br/5564372426013611 \\ http://orcid.org/0000-0002-1894-6481 \\ fernando.luiz.2327@gmail.com \\ Elaine Cristina Araújo (D) \\ Universidade Federal de Campina Grande, Brasil \\ https://orcid.org/0000-0002-6288-8469 \\ crys_lainne@yahoo.com.br
}

Referencing this:

SILVA, M. J.; BARROS, A. T.; SILVA, É. J. A.; MELO, L. D. M.; FARIAS, F. L. B.; ARAÚJO, E. C.. Análise de parâmetros físicos, químicos e biológicos necessários à qualidade de adubo orgânico oriundo de processo de compostagem realizado na Universidade Estadual da Paraíba, PB. Revista Ibero Americana de Ciências Ambientais, v.12, n.7, p.377389, 2021. DOI: http://doi.org/10.6008/CBPC2179-

$\underline{6858.2021 .007 .0034}$ 


\section{INTRODUÇÃO}

No contexto social vigente, embora esteja presente a Lei $12.305 / 2010$, que regulamenta a Política Nacional dos Resíduos Sólidos no Brasil, ainda existem diversos problemas relacionados à acomodação dos resíduos sólidos presentes em diversos municípios (BRASIL, 2010).

É imprescindível salientar que o descarte inadequado dos resíduos sólidos proporciona problemas, exacerbadamente, para o meio ambiente e à população. Para a humanidade, ocasiona problemas como doenças oriundas da proliferação de insetos, roedores e outros vetores. Para o meio ambiente, esta prática proporciona poluição do ar, do solo, contaminação da água dos rios e dos mares, assoreamento de rios e canais, entupimentos de galerias, além da morte de diversos seres vivos (JUNKES, 2002; ALCANTARA, 2010).

Nos resíduos sólidos produzidos no Brasil está presente um grande percentual de matéria orgânica, constituída por restos de alimentos, casca de frutas, legumes e resíduos de jardinagem (ALCANTARA, 2010; BRASIL, 2010).

A compostagem é uma alternativa para solucionar os problemas relacionados ao descarte inadequado de resíduos sólidos orgânicos, por ser um método biológico aeróbico, onde a matéria orgânica é reciclada, tratada e estabilizada em um material de ótima qualidade (BUDZIAK; MAIA; MANGRICH, 2004). É um processo eficaz e de baixo custo financeiro (COSTA et al., 2009), atuando de maneira eficaz na redução de organismos prejudiciais do adubo orgânico, que ocorre por conta da competição entre os organismos que estão presentes no processo de compostagem e dos parâmetros abióticos, como as temperaturas altas por um determinado período. $\mathrm{O}$ adubo orgânico obtido através do processo de compostagem possibilita o melhoramento das características físicas, químicas e biológicas do solo, principalmente na agricultura (PIRES, 2006; BERNAL et al., 2009; CARTHY et al., 2011).

Desta forma, o conhecimento e a divulgação do que seja e de como funciona a compostagem é de extrema importância biológica e social. Em primeiro lugar, pela busca de maior sensibilização ecológica das pessoas em relação à problemática dos resíduos sólidos, e em segundo lugar, porque este método auxilia na diminuição dos resíduos sólidos urbanos (RSUs), reciclando os nutrientes presentes nos resíduos sólidos orgânicos, transformando-os em adubo orgânico de qualidade.

Deste modo, a presente pesquisa teve como objetivo monitorar os parâmetros físicos, químicos e biológicos de um sistema de compostagem montado na Universidade Estadual da Paraíba (UEPB).

\section{MATERIAIS E MÉTODOS}

Foram utilizados $72 \mathrm{~kg}$ de resíduos sólidos orgânicos domiciliares no sistema de compostagem, $34 \mathrm{~kg}$ provenientes das residências de estudantes do ensino fundamental I da Escola Municipal Padre Cornélio de Boer, situada no bairro Santa Cruz, na qual estava sendo aplicado um projeto de extensão sobre educação ambiental, e mais $38 \mathrm{~kg}$ oriundos de residências do bairro Malvinas, os quais eram excedentes de resíduos orgânicos advindos da coleta de outro projeto que acontecia em paralelo, ambos na cidade de Campina Grande - PB. 
Todo o material foi misturado com auxílio de pás, a fim de homogeneizar o substrato. Posteriormente, os resíduos sólidos orgânicos foram triados, pesados e misturados com folhas secas (estruturante) antes de serem colocados nas composteiras.

O Sistema de Tratamento Descentralizado de Resíduos Sólidos Orgânicos (SITRADERO) é um anexo do Laboratório de Extensão e Pesquisa em Gestão e Educação Ambiental (Lab.GGEA/UEPB), instalado próximo ao prédio 2 das Três Marias. Teve sua estrutura desenvolvida por Araújo (2018), com madeira, telas e lonas plásticas, com o objetivo de evitar a entrada de animais, chuvas ou a incidência direta do sol, ou seja, fatores que pudessem interferir no processo de decomposição. Para os experimentos em questão, o sistema foi montado em agosto e desmontado em dezembro de 2018 (104 dias).

Foram dispostas no local (área de $16 \mathrm{~m}^{2}$ ) três composteiras móveis de concreto retangular (CCR), desenvolvidas por Nascimento (2015). Elas são formadas por dois compartimentos para facilitar na hora do revolvimento, com redução de $0,25 \mathrm{~m}$ nas laterais de cada compartimento e apresentando as seguintes dimensões: $0,30 \mathrm{~cm}$ de largura, $0,50 \mathrm{~cm}$ de comprimento e $0,50 \mathrm{~cm}$ de altura. 0 volume total de cada uma é de $0,075 \mathrm{~m}^{3}$.

Cada composteira de concreto tem a capacidade de armazenar $30 \mathrm{~kg}$ de resíduos, porém, como o estruturante utilizado foram as folhas e elas têm um grande volume, cada composteira ficou com $25 \mathrm{~kg}$, totalizando $75 \mathrm{~kg}$ de composto orgânico no sistema. A composição de cada uma consistia em $80 \%$ de resíduos orgânicos e $20 \%$ de estruturante, misturados até formarem uma mistura homogênea, da qual foram retiradas amostras de $25 \mathrm{~g}$ para as análises iniciais, uma vez na semana, durante o revolvimento.

O monitoramento teve início com as análises de $\mathrm{pH}$, umidade, sólidos totais e voláteis, presença de mesoinvertebrados e ovos de helmintos, uma vez que era necessário analisar as concentrações do composto, bem como identificar quais os organismos que estariam presentes. Um dia após a montagem do sistema, iniciaram-se as análises de temperatura.

Após a montagem do sistema de tratamento, o monitoramento se deu por meio de análises físicas, químicas e biológicas (Quadro 1), cujos resultados foram arquivados em planilha do Excel (for Windows), analisados e representados por meio de gráficos, tabelas.

Quadro 1: Parâmetros analisados durante o monitoramento do SITRADERO.

\begin{tabular}{|l|l|l|l|}
\hline \multirow{4}{*}{ Químico } & Parâmetros & Frequência & Método \\
\cline { 2 - 4 } & Sólidos Totais Voláteis (\%ST) & Uma vez na Semana & Gravimétrico \\
\cline { 2 - 4 } & Potencial Hidrogeniônico (pH) & Uma vez na Semana & Potenciômetro \\
\cline { 2 - 4 } & Carbono orgânico total (\%COT) & Uma vez na Semana & Kiehl (1998) 1,8xSTv \\
\cline { 2 - 4 } & Nitrogênio Total (\%NTK) & Final & Método de Kjeldhal \\
\cline { 2 - 4 } & Potássio (\%ST) & Final & Fotômetro de Chama \\
\cline { 2 - 4 } & Fósforo Total (\%ST) & Final & Fotômetro de Chama \\
\hline \multirow{5}{*}{ Físicos } & Temperatura (oㄷ) & Diariamente & Termômetro \\
\cline { 2 - 4 } & Aeração & Duas vezes por semana & Silva (2008) \\
\cline { 2 - 4 } & Umidade (\%) & Uma vez na Semana & Gravimétrico \\
\hline & Quantidade de ovos de Helmintos (ovos\%gST) & Início e Final & Meyer et al. (1978) modificado por Silva (2008) \\
\cline { 2 - 3 } & Mesoinvertebrados (Ind/gST) & Uma vez na Semana & Silva (2008) \\
\hline
\end{tabular}

Análises Físicas: Temperatura, umidade e aeração (ou oxigenação)

As aferições da Temperatura (Co) foram efetuadas diariamente nas três composteiras, de maneira 
similar, com auxílio de três termômetros de haste de mercúrio. Foram obtidas a temperatura em três pontos do composto, em cada área do substrato: superfície, centro e base, adquirindo uma média de cada área. Também foi verificada a temperatura ambiente do local onde foi montado o sistema, com objetivo de compará-la com a temperatura do sistema em estudo.

As análises de umidade ocorreram semanalmente, de acordo com a metodologia proposta por Nascimento (2015). O processo de aeração foi feito duas vezes na semana, manualmente, utilizando uma pá agrícola para mover o substrato de um compartimento a outro da composteira, com objetivo de homogeneizar o composto e fornecer o oxigênio necessário à ação aeróbica dos organismos presentes.

\section{Análises Químicas: Potencial Hidrogeniônico (pH), Carbono Orgânico Total (\% COT), Sólidos Voláteis Totais (\%SVT) e Macronutrientes}

Para obtenção do valor de $\mathrm{pH}$, oram utilizados $25 \mathrm{~g}$ de composto em $125 \mathrm{ml}$ de água destilada. A solução foi homogeneizada e levada ao pHmetro, onde ocorreram as análises semanais.

A quantidade de carbono orgânico total do composto foi obtida por meio da calcinação, sendo necessário utilizar o valor de 1,8 para a conversão da taxa de sólidos totais voláteis em carbono orgânico total, de acordo com Jiménez et al. (1992) e Kiehl (1998).

O teor de sólidos totais foi obtido por meio do método de calcinação. As amostras foram coletadas, pesadas em uma balança e levadas para uma estufa, por um período de 24 horas a 105 ㄷ.

Para obter o potencial de sólidos fixos e voláteis utilizou-se $25 \mathrm{~g}$ do composto de cada amostra, submetendo à calcinação por $550^{\circ} \mathrm{C}$ na mufla durante o tempo de duas horas. Após esta etapa, as amostras foram pesadas sucessivamente e devolvidas à mufla por mais uma hora, sendo este processo repetido até se obter a estabilidade (P2).

As análises de macronutrientes realizadas foram: Nitrogênio Total (\%NT); Potássio (\%ST), Fósforo (\%ST) e Relação Carbono/Nitrogênio (C:N).

Para obtenção do \%NT, foram pesados cerca de $50 \mathrm{~g}$ do adubo orgânico (composto obtido ao final do processo) e estes foram encaminhados ao Laboratório de Análise de Tecido de Plantas, localizado na Universidade Federal da Paraíba/Campus II/Areia-PB onde foi realizada a análise.

As análises de Potássio (\%ST) e Fósforo (\%ST) também foram realizadas apenas ao final do processo, utilizando $50 \mathrm{~g}$ do adubo orgânico produzido, a fim de adquirir dados relacionados ao teor de cada nutriente do adubo. Para isto, as análises foram realizadas no Laboratório de Irrigação e Salinidade, localizado na Universidade Federal de Campina Grande (UFCG), Campus I/Campina Grande - PB.

A relação $\mathrm{C}: \mathrm{N}$ foi expressa através dos valores obtidos nas análises de carbono orgânico total Kiehl (1998) e nitrogênio total através do método de Kjeldhal.

\section{Análises Biológicas: Mesoinvertebrados e ovos de Helmintos}

Foram coletados $25 \mathrm{~g}$ de material para cada análise semanal de mesoinvertebrados. As amostras foram colocadas em placas de Petri e com auxílio de uma lupa binocular foi possível realizar a coleta dos 
indivíduos. A contagem e classificação taxonômica dos espécimes foram realizados de acordo com a metodologia sugerida por Silva (2021).

As análises de ovos de helmintos foram realizadas a partir de coletas no início e ao final do processo de compostagem, com finalidade de avaliar a eficiência sanitária do mesmo. O método utilizado para as análises foi baseado em Meyer et al. (1978) e modificado por Silva (2008).

Desde modo, para se obter a viabilidade dos ovos de helmintos, foi realizada uma coloração com solução de safranina a $1 \%$, com objetivo de verificar a permeabilidade da membrana vitelina dos ovos ao microscópio (ZERBINI et al., 1999).

Após a realização de todas as análises necessárias, o sistema de compostagem foi desmontado, pois todos os parâmetros indicavam estabilização.

\section{RESULTADOS}

\section{Caracterização das Análises Físicas}

\section{Temperatura}

O sistema de compostagem iniciou com temperaturas médias: Superfície $\left(43,4^{\circ} \mathrm{C}\right)$, Centro $\left(39,2^{\circ} \mathrm{C}\right)$, base $\left(34,3^{\circ} \mathrm{C}\right)$, identificando uma fase mesófila. Com o decorrer do processo de decomposição aeróbica e a ação dos organismos autóctones, os valores de temperatura aumentaram em todo o sistema alcançado a marca de $54,4^{\circ} \mathrm{C}$ na superfície, $55,4^{\circ} \mathrm{C}$ no centro e $51^{\circ} \mathrm{C}$ na base, sugerindo fase de degradação ativa. Após esta fase, a temperatura começou a diminuir atingindo a fase de maturação, com a temperatura próxima à temperatura até o final do processo de compostagem: $24,8^{\circ} \mathrm{C}$ na superfície, $24,7 \circ \mathrm{C}$ no centro e $26 \circ \mathrm{C}$ na base (Figura1).

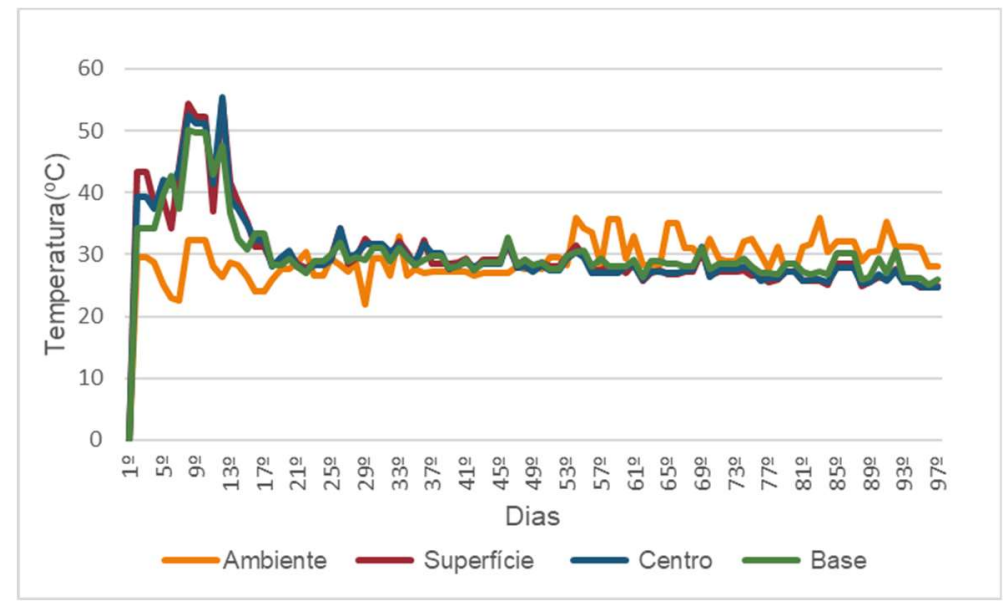

Figura 1: Temperatura média do sistema de compostagem. Fonte: Silva (2020).

Os resultados obtidos corroboram com Brito (2015), que afirma que a temperatura pode chegar a 40 ou $50^{\circ} \mathrm{C}$ por volta do segundo ou terceiro dia, podendo diminuir conforme os resíduos vão sendo degradados. Segundo ele, os percentuais durante o processo de compostagem levam em consideração a velocidade que ocorre a decomposição, ou seja, a velocidade que os organismos crescem e atuam no experimento. Após o dia 97ำ não houve verificação da temperatura pois a mesma estava estabilizada. 


\section{Teor de Umidade}

O teor de umidade obtido inicialmente foi de $71 \%$, valor considerado alto de acordo com a literatura que considera valores iniciais do experimento entre 50\% e 60\% (CARRINGTON, 2001; RUSSO, 2003; BIDONE, 2007; KUTZE, 2008; NEKLYUDO et al., 2008). Logo, o uso de folhas como estruturante e revolvimentos semanais se tornaram excelentes alternativas para o controle do teor de umidade e condições adequadas para ação dos organismos.

Ao término do experimento, o valor do teor de umidade foi de $32 \%$, atendendo à Instrução Normativa no 25/2009 do Ministério da Agricultura, pecuária e abastecimento para fertilizantes orgânicos (BRASIL, 2009), como pode ser visto na figura 2, a seguir.

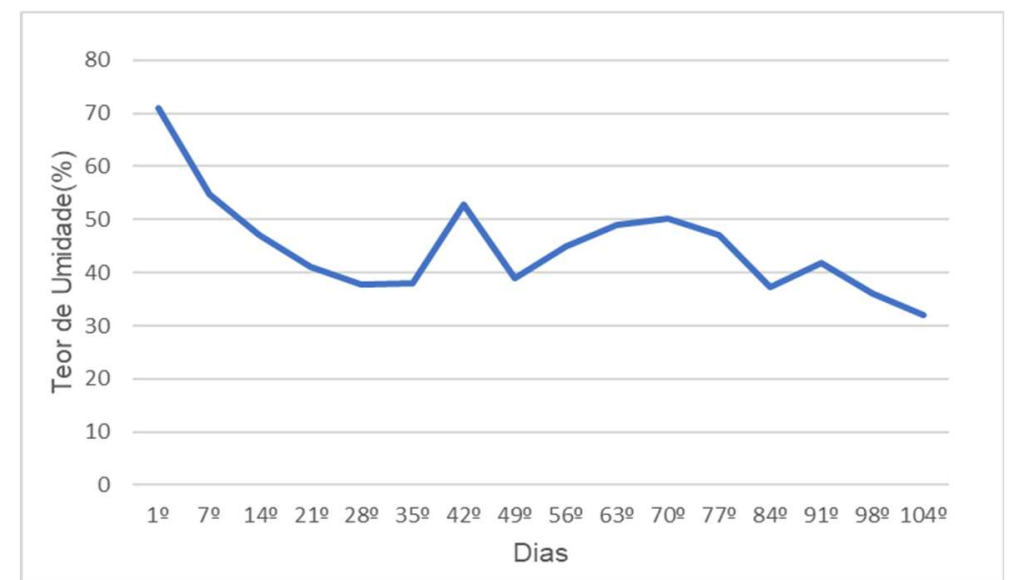

Figura 2: Valores médios referentes ao Teor de umidade (\%). Fonte: Silva (2020).

\section{Potencial Hidrogeniônico $(\mathrm{pH})$}

$\mathrm{O} \mathrm{pH}$ inicial dos resíduos sólidos orgânicos foi 4,7 (ácido) e o pH ao final do monitoramento atingiu 8,1 (básico), conforme pode ser observado na figura 3.

De acordo com Araújo (2018), o valor inicial encontrado é característico do início do processo de compostagem e estimula a proliferação de fungos e bactérias. Sendo assim, sabe-se que no começo do experimento de compostagem há a proliferação dos organismos e o material apresenta um pH ácido, entre 4,5 a 5,5, consequência das ações das bactérias sintetizadoras de ácidos minerais. Por outro lado, no período intensivo da atuação microbiana, o pH encontrado é em média de 6,5 a 8,0 e no período de maturação do material, o pH pode variar entre 7,5 e 9,0 (BARTOLDI et al., 1983; FERNANDES et al., 1999; BIDONE, 2001; RUSSO, 2003).

Lima Júnior (2015) afirma que é de fundamental importância ter domínio deste parâmetro, evitando teores drasticamente ácidos ou básicos, pois apenas poucas espécies de microrganismos podem existir em tais situações. Nestes casos, o reparo do $\mathrm{pH}$ pode ser feito com elementos de substratos como cinzas para se obter um pH básico e cascas de batatas para pH ácido. 


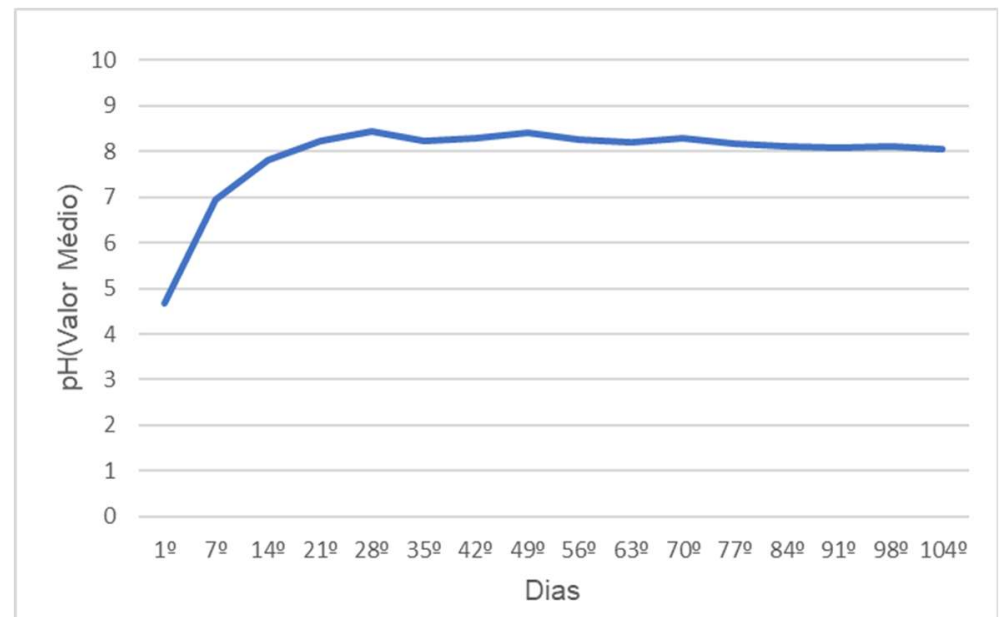

Figura 3: Valores médios do pH ao longo do monitoramento do sistema de compostagem. Fonte: Silva (2020).

\section{Análises Químicas}

\section{Sólidos Totais, Fixos e Voláteis}

Os percentuais iniciais adquiridos para Sólidos totais, sólidos voláteis e sólidos fixos foram $28,1 \%$, $76,0 \%$ e $23,1 \%$, respectivamente. Tais valores demonstraram a alta concentração de matéria orgânica no início do processo.

A evolução dos resultados de sólidos totais, sólidos voláteis e sólidos fixos no sistema durante o monitoramento está representada na figura 4.

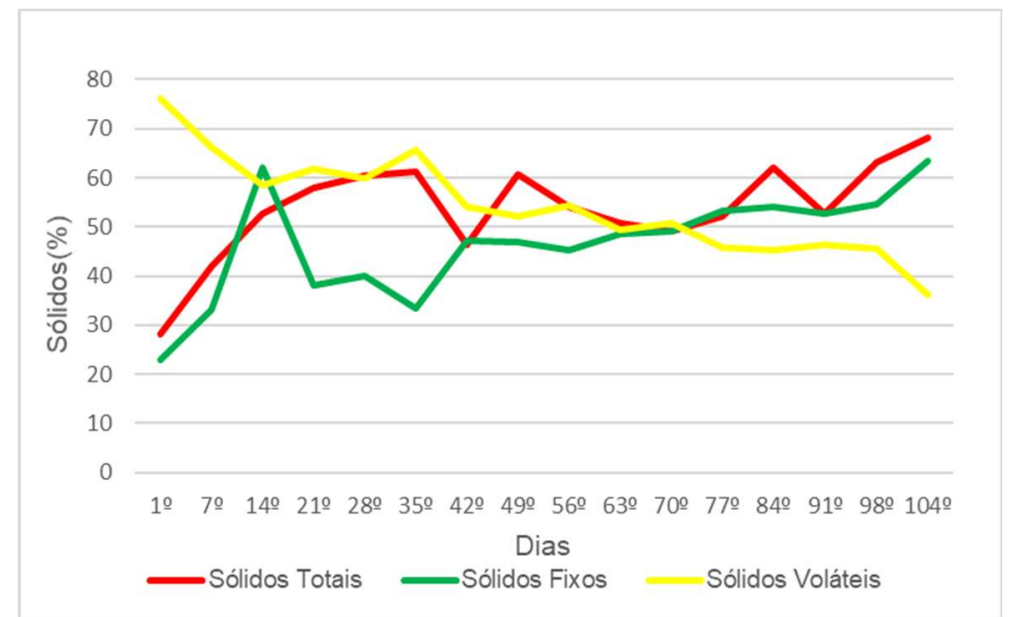

Figura 4: Valores médios de Sólidos Totais, Sólidos Fixos e Sólidos Voláteis no sistema. Fonte: Silva (2020).

\section{Carbono Orgânico Total (COT)}

Os valores médios de COT encontrados, no início e no final do processo de compostagem, foram $42,6 \%$ e $20,0 \%$, respectivamente, demonstrando que houve a estabilidade do composto (Figura 5).

De acordo com Dores-Silva et al. (2013), durante o processo de estabilização da matéria orgânica, ocorre a mineralização de uma parte do material e a humificação da outra parcela. Logo, o teor de matéria orgânica diminui ao longo do processo de estabilização, uma vez que parte do carbono presente no material inicial passou para a atmosfera na forma de $\mathrm{CO}_{2}$, por meio da respiração dos microrganismos que degradam a matéria orgânica. 


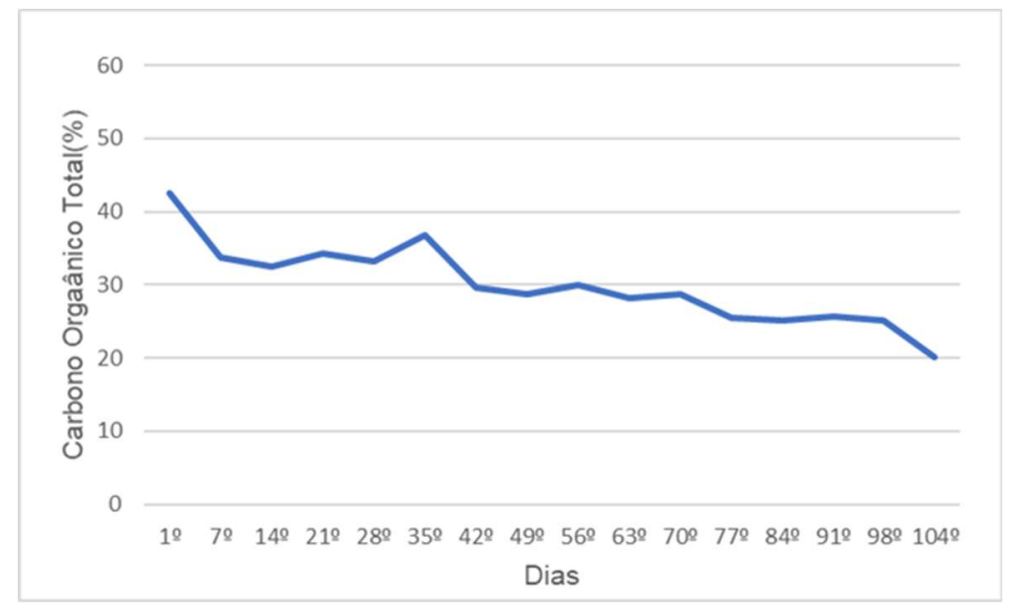

Figura 5: Percentual médio de Carbono Orgânico Total. Fonte: Silva (2020).

\section{Relação Carbono: Nitrogênio}

A relação C: $N$ encontrada ao término do processo foi 20:1. Logo, pode-se afirmar que o composto atingiu os padrões estabelecidos pela Instrução Normativa no 25, de 23 de julho de 2009 do Ministério da agricultura, pecuária e abastecimento para fertilizantes orgânicos, que determina como valor ideal a relação de no máximo 20:1 (BRASIL, 2009).

\section{Análises Biológicas}

\section{Ovos de Helmintos}

O valor obtido para os ovos de helmintos foi de 1,33 ovos gST (Tabela 1). Este percentual foi considerado baixo se comparado ao valor obtido por Araújo (2018), que foi de 14,3 ovos/gST. Por outro lado, foi um valor próximo aos obtidos por Silva et al. (2011) e Silva et al. (2013), que foram 0,6 ovos/gST e 0,89 ovos/gST, respectivamente.

Tabela 1: Concentração de Ovos de Helmintos (viáveis e não viáveis).

\begin{tabular}{l|l|l|l|l}
\hline Espécie & Viável (n) & Não Viável (n) & Total (n) & Viável (\%) \\
\hline Ascaris lumbricoides & 01 & 01 & 02 & $50 \%$ \\
\hline
\end{tabular}

A análise de ovos de helmintos nos resíduos orgânicos tem o objetivo de analisar a qualidade sanitária dos resíduos, acredita-se que o valor encontrado pode estar relacionado aos tipos de resíduos sólidos orgânicos usados no experimento e que estes tenham influenciado no resultado.

Segundo Silva et al. (2010), o surgimento dos ovos de helmintos nos resíduos sólidos orgânicos domiciliares pode ocasionar doenças endêmicas. De acordo com pesquisas realizadas cerca de 1,5 bilhões de indivíduos ao redor do mundo estão ou já estiveram parasitadas por alguma espécie de helminto (WHO, 2015).

\section{Diversidade de Mesoinvertebrados}

Foram coletados 691 mesoinvertebrados durante o experimento, dentre eles, aracnídeos (ácaros) e 
insetos. A Figura 6 apresenta a diversidade taxonômica encontrada.
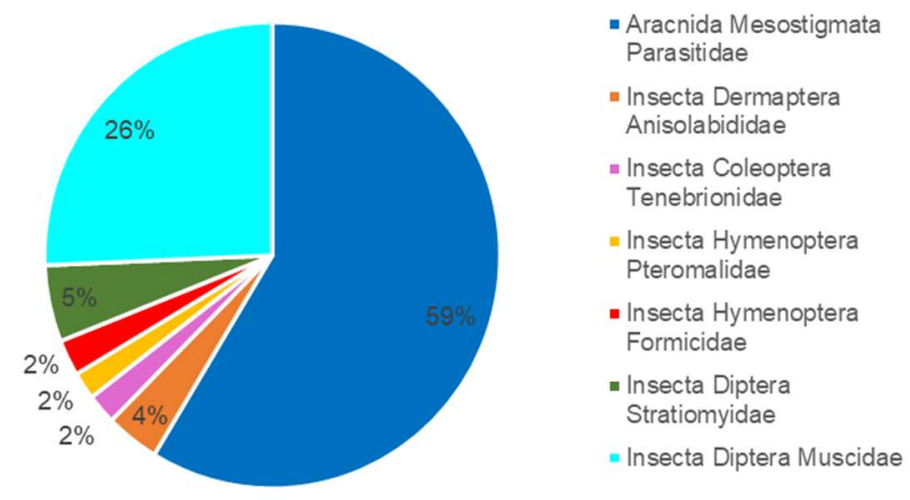

Figura 6: Diversidade Taxonômica de Mesoinvertebrados no sistema de compostagem. Fonte: Silva (2020).

A ordem que mais se destacou entre os indivíduos coletados foi a Mesostigmata (família Parasitidae; 59\% dos indivíduos), seguida dos Díptera (família Muscidae; 26\%). Entretanto, a presença de todos os indivíduos que participaram do processo de compostagem é de extrema importância na degradação da matéria orgânica.

Foi possível observar que à medida que a faixa de tolerância dos indivíduos chegava ao limite, o número de indivíduos decaía, surgindo outros indivíduos. Ao término do monitoramento, já não foi mais visualizado nenhum indivíduo.

\section{Fungos}

Foram visualizados alguns fungos durante a realização do experimento, porém eles não foram identificados (Figura 7). Estiveram presentes no experimento desde o 7으 dia, quando os maiores níveis de temperatura começaram a se estabelecer e a umidade se encontrava em torno de $54,73 \%$.

O número de fungos visíveis começou a declinar a partir do 39 dia, quando a temperatura já estava próxima à temperatura ambiente e a umidade se encontrava entre 38,0 e 52,7\%, demostrando que o material celulósico em que se desenvolveram tinha diminuído.
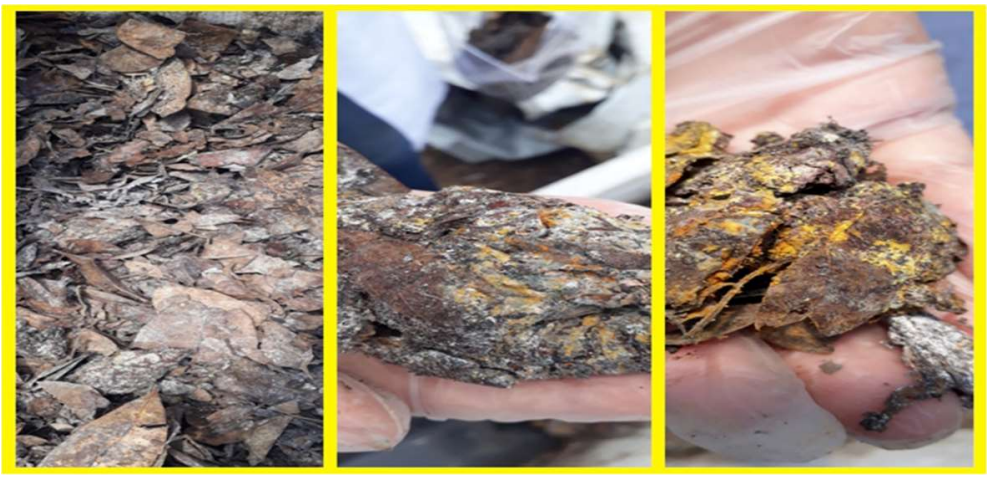

Figura 7: Fungos presentes no sistema de compostagem. Fonte: Silva (2018).

Segundo Rebollido et al. (2008), os fungos são de fundamental importância durante a fase de 
estabilização, bem como na fase de maturação da matéria orgânica contribuindo para que elas ocorram de forma eficaz. Eles possuem o sistema enzimático ativo, o que possibilita a decomposição da lignocelulose (BUG et al., 2011).

\section{Caracterização sanitária do composto final produzido}

Após 104 dias de experimento, o material passou a ter coloração escura e odor de terra, indicando a sua maturação (FUNDACENTRO, 2002), ou seja, ocorreu a estabilização do composto. A partir disso, foi realizado o peneiramento e obtido um composto, que foi classificado em rejeito, farelo e pó (Figura 8).

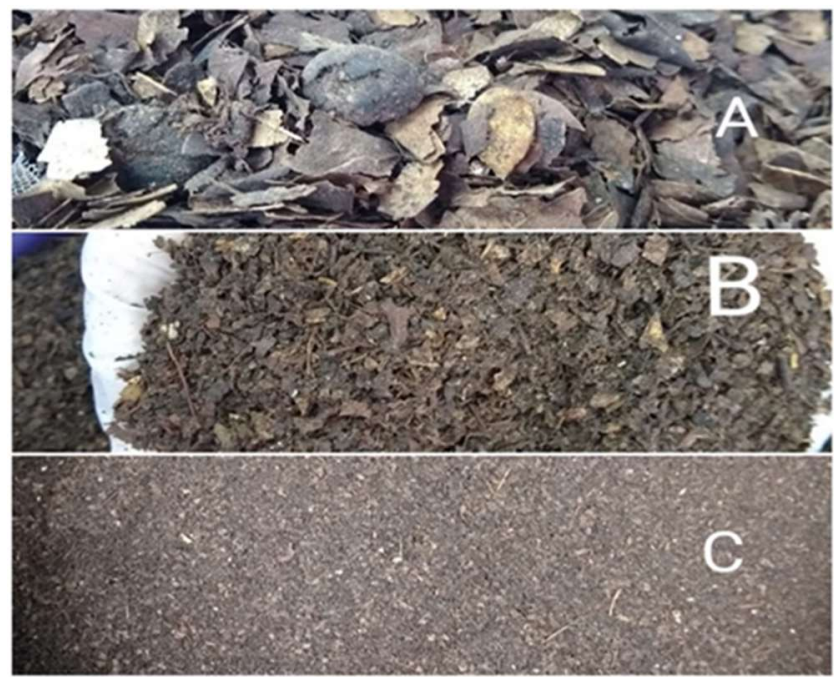

Figura 8: Composto gerado no sistema de compostagem. Rejeito (a); farelo (b); pó (c). Foto: Silva (2018).

Ao final do experimento, foram gerados $20 \mathrm{~kg}$ de adubo orgânico. A massa final do substrato obtido no sistema CCR correspondeu a: 1) composto tipo pó $(9,850 \mathrm{~kg}), 2)$ composto tipo farelo $(4,050 \mathrm{~kg})$ e 3) composto tipo rejeito $(6,100 \mathrm{~kg})$.

Foram compostados $75 \mathrm{~kg}$ iniciais de resíduos sólidos justamente com o estruturante, e destes apenas 6,100 kg se transformaram em rejeito. O mesmo é constituído basicamente por pedaços de galhos, restos de folhas de árvores, algumas sementes de mangas, cascas de laranjas, sabugos e palhas de milho e alguns ossos de animais. Sendo assim, conclui-se que a prática da compostagem na produção do adubo orgânico é uma alternativa viável e sustentável para a eliminação do lixo orgânico gerado em qualquer comunidade ou município, diminuindo o volume de resíduos que seriam encaminhados de forma inadequada para lixões e aterros sanitários, além de destruir bactérias patogênicas, por exemplo (SILVA, 2016).

A qualidade sanitária do composto final foi determinada levando-se em consideração a faixa indicativa para os parâmetros analisados na Instrução Normativa no 25/2009, do Ministério da agricultura, pecuária e abastecimento para fertilizantes orgânicos (BRASIL, 2009), as quais estão expressas na tabela 2.

No composto final não foram encontrados ovos de helmintos, logo é possível afirmar que o sistema de compostagem foi eficiente para a higienização e o adubo orgânico poderá ser utilizado em plantações sem promover a contaminação do solo e doenças aos animais.

Com exceção do potássio, que apresentou valores abaixo da faixa indicativa, todos os demais 
parâmetros se enquadraram nas exigências da Instrução Normativa no 25/2009 (BRASIL, 2009). Segundo Araújo (2018), o valor potássio encontrado pode estar relacionado com o baixo teor desse mineral nos alimentos da população doadora dos resíduos. Mesmo assim, o resultado foi considerado extremamente satisfatório, uma vez que o potássio pode ser corrigido a partir da adição alternativa de cascas de ovos e cascas de bananas trituradas ou borra de café.

Tabela 2: Características do composto Final.

\begin{tabular}{|c|c|c|c|}
\hline \multirow{3}{*}{ Parâmetros } & \multicolumn{2}{|l|}{ Valores médios } & \multirow{3}{*}{$\begin{array}{l}\text { Faixa Indicativa } \\
\text { IN no 25/2009 }\end{array}$} \\
\hline & \multicolumn{2}{|l|}{ CCR } & \\
\hline & Substrato inicial & Composto Final & \\
\hline pH & 4,7 & 8,1 & $>6,5$ \\
\hline SVT (\%) & 76,0 & 36,2 & $<40$ \\
\hline СОT (\%) & 42,6 & 20 & $8<25$ \\
\hline Teor de Umidade (\%) & 71,2 & 32 & $<50$ \\
\hline Helmintos (OVOS/gst) & 1,3 & 0,0 & $<0,25$ \\
\hline Nitrogênio (\%ST) & - & 1,3 & $>1$ \\
\hline Potássio (\%ST) & - & 0,8 & $>1$ \\
\hline Fósforo (\%ST) & - & 4,2 & $>1,6$ \\
\hline
\end{tabular}

\section{CONCLUSÕES}

Pode-se afirmar que todo o processo de compostagem ocorreu de forma satisfatória, ocorrendo a estabilização do composto ao final de 104 dias, o qual foi peneirado e classificado em rejeito, farelo e pó. Todos os nutrientes, com exceção do teor de potássio, estavam de acordo com a Instrução Normativa no 25/2009, indicando que o composto orgânico obtido pode ser utilizado como adubo para as plantas. 0 sistema de compostagem provou ser um ótimo meio de sanitização, pois os ovos de helmintos, os fungos, os mesoinvertebrados, além dos aracnídeos e insetos não foram mais observados ao final do experimento.

Sendo assim, considera-se que o entendimento e a divulgação do que seja e de como funciona a compostagem é de grande importância biológica e social e quanto mais cedo a educação ambiental for introduzida na educação básica, abordando diversos temas do cotidiano dos estudantes, mais conscientes e envolvidos em ações sustentáveis estes serão. Com relação ao adubo orgânico produzido, sugere-se que sejam realizados estudos complementares a respeito da fitotoxicidade, antes da sua aplicação em jardins e hortas comunitárias.

A compostagem pode ser feita de forma descentralizada em comunidades de todo o país, uma vez que se trata de um processo de baixo custo. A sua realização contribui de maneira eficaz na diminuição de resíduos orgânicos que seriam misturados a outros resíduos e direcionados para aterros ou lixões. Sendo assim, sugere-se que mais ações como essas sejam desenvolvidas em várias escolas do país.

\section{REFERÊNCIAS}

ALCANTARA, A. J. O.. Composição gravimétrica dos resíduos sólidos urbanos e caracterização química do solo da área de disposição final do município de Cáceres-MT.

Dissertação (Mestrado em Ciências Ambientais) -

Universidade do Estado de Mato Grosso, Cáceres, 2010.

ARAÚJO, E. C. S.. Organismo que participam das diferentes fases do tratamento aeróbico de resíduos orgânicos domiciliares. Dissertação (Mestrado em Ciências e Tecnologia Ambiental) - Universidade Estadual da Paraíba, Campina Grande, 2018

BERNAL, M. P.; ALBUQUERQUE, J. A.; MORAL, R. Composting of animal manures and chemical criteria for compost maturity assessment: a review. Bioresource Technology, v.100, p.5444-5453, 2009. 
BIDONE, F. A.. Resíduos Sólidos Provenientes de coletas especiais: eliminação e valorização. Brasília: FINEP/PROSAB, 2001.

BIDONE, R. F.. Tratamento de lixiviado de aterro sanitário por um sistema composto por filtros anaeróbios seguidos de banhados construídos: Estudo de caso: Central de resíduos do recreio, em Minas do Leão/MS. Dissertação (Mestrado em hidráulica e saneamento) - Universidade de São Paulo, São Paulo, 2007.

BRASIL. Instrução Normativa N. 25, de 23 de julho de 2009. Aprova as Normas sobre as especificações e as garantias, as tolerâncias, o registro, a embalagem e a rotulagem dos fertilizantes orgânicos simples, mistos, compostos, organominerais e biofertilizantes destinados à agricultura. Brasília: Ministério da Agricultura, 2009.

BRASIL. Lei n. 12.3051, de 2 de agosto de 2010. Política Nacional de Resíduos Sólidos. 2010.

BRASIL. Ministério do Meio Ambiente. Manual para implantação de compostagem e de coleta seletiva no âmbito de consórcios públicos. Brasília: MMA, 2010.

BRITO, L. M.. Compostagem para a Agricultura Biológica II. Manual de Agricultura Biológica - Terras de Bouro. 2015. p.21.

BUDZIAK, C. R., MAIA, C. M. B. F.; MANGRICH, A. S. Transformações químicas da matéria orgânica durante a compostagem de resíduos da indústria madeireira. Revista Química Nova, v.27, n.3, p.399-403, 2004.

BUG, T. D. H.; AHMAND, M.; HARDIMAN, E. M.; RAHMANPOUR, R.. Pathways for degradation of liginin in bacteria and fungi. Natural Product Reports, v.18, n.12, p.1871-196, 2011.

CARRINGTON, E. G.. Evaluation of Sludge treatments for pathogen reduction. Final Report. Luxembourg: European communities, 2001.

COSTA, M. S. S. M.; DECARLIL, D.; PELÁ, A.. Compostagem de resíduos sólidos de frigorífico. Revista Brasileira de Engenharia Agrícola Ambiental, Campina Grande, v.13, n.1, p.100-107, 2009.

CARTHY, G. M.; LAWLOR, P. G.; COFFEY, L.; NOLAN, T.; GUTIERREZ, M.; GARDINER, G. E.. Compostagem domiciliar: implantação e avaliação do processo. Bioresource Technology, v.102, p.9059-9067, 2011.

DORES-SILVA, P. R.; LANDGRAF, M. D.; REZENDE, M. O. O.. Processo de Estabilização de Resíduos Orgânico: Vermicompostagem versus Compostagem. Revista Química Nova, São Paulo, v.36, n.5, 2013.

FERNANDES, F.; SILVA, S. M. C. P.. Manual prático para a compostagem de biossólidos. Rio de Janeiro: ABES, 1999.

KIEHL, E. J.. Manual de compostagem: maturação e qualidade do composto. Piracicaba, 1998.

JUNKES, M. B.. Procedimentos para aproveitamento de resíduos sólidos urbanos em municípios de pequeno porte. Dissertação (Mestrado em Engenharia de Produção) Universidade Federal de Santa Catarina, Florianópolis, 2002.

JIMÉNEZ, E. I.; GARCIA, V. P.. Relationships between organic carbon and total organic matter in municipal solid wastes and city refuse composts. Bioresource Techonology, v.41, p.265-272, 1992.

LIMA JÚNIOR, R. G. S.. Estratégias de compostagem como pré-tratamento de resíduos sólidos orgânicos. Tese (Doutorado em Engenharia Civil) - Universidade Federal do Rio de Janeiro, Rio de Janeiro, 2015.

MEYER, K. B.; MILLER, K. D.; KANESHIRO, S.. Recovery of Ascaris eggs from sludge. Journal of parasitology: The American Society of Parasitologist, v.64, n.2, p.380-383, 1978.

NEKLYUDO, A. D.; FEDOTOV, G. N.; IVANKIN, A. N.. Intensification of composting processes by aerobic microorganisms: a review. Applied Biochemistry and Microbiology, v.44, n.1, 2008.

NASCIMENTO, C.. Sistema de Tratamento Descentralizado de Resíduos Sólidos Orgânicos no Bairro Malvinas, Campina Grande-PB. Dissertação (Mestrado em Ciências e Tecnologia Ambiental) - Universidade Estadual da Paraíba, Curitiba, 2015.

PIRES, A. M. M.. Uso agrícola de composto de lixo urbano: benefício ou prejuízo. EMBRAPA, 2006.

RUSSO, M. A. T.. Tratamento de resíduos sólidos. Dissertação (Mestrado em Engenharia Civil) - Universidade de Coimbra, Coimbra, 2003.

REBOLLIDO, R.; MARTÍNEZ, J.; AGUILERA, Y.; MELCHOR, K.; KOERNER, I.; STEGMANN, R.. Microbial population during composting process of organic fraction of municipal solid waste. Applied Ecology and Environmental Research, v.6, n.3, p.61-67, 2008.

SILVA, M. M. P.. Tratamento de lodos de tanques sépticos por co-compostagem para os municípios do semiárido Paraibano: alternativa para mitigação de impactos ambientais. Tese (Doutorado) - Universidade Federal de Campina Grande, Campina Grande, 2008.

SILVA, M. M. P.. Tratamento de lodos de tanques sépticos e resíduos sólidos orgânicos domiciliares (livro eletrônico): Transformando problema em solução. Nova Xavantina: Pantanal, 2021.

SILVA, M. M. P.; SOUZA, J. T.; CEBALLOS, B. S. O.; FEITOSA, W. B. S.; LEITE, V. D.. Avaliação sanitária de resíduos sólidos orgânicos domiciliares em municípios do semiárido paraibano. Revista Caatinga, v.23, n.2, p.87-92, 2010.

SILVA, M. M. P.; OLIVEIRA, A. G.; LEITE, V. D.; SOARES, L. M. P.; OLIVEIRA, S. C.. Avalição de Sistema de tratamento descentralizado de resíduos sólidos orgânico domiciliares em Campina Grande-PB. In: CONGRESSO BRASILEIRO DE ENGENHARIA SANITÁRIA E AMBIENTAL, 26. Anais. Porto Alegre: ABES, 2011. 
Análise de parâmetros físicos, químicos e biológicos necessários à qualidade de adubo orgânico oriundo de processo de compostagem realizado na Universidade Estadual da Paraíba, PB

SILVA, M. J.; BARROS, A. T.; SILVA, É. J. A.; MELO, L. D. M.; FARIAS, F. L. B.; ARAÚJO, E. C.

SILVA, M. M. P.; SOUZA, D. M.; SILVA, P. A.; SILVA, E. H.; JUSTINO, E. D.. Contaminação de resíduos sólidos orgânicos domiciliares gerados em domicílios situados na zona urbana de Campina Grande-PB. In: ASSOCIAÇÃO BRASILEIRA DE ENGENHARIA SANITÁRIA E AMBIENTAL, 27. Anais. Rio de Janeiro, 2013.

SILVA, A. S. F.. Avaliação do processo de compostagem com diferentes proporções de resíduos de limpeza urbana e restos de alimentos. Dissertação (Mestrado) - Universidade Federal de Pernambuco, Recife, 2016.
WHO. World Health Organization. Ivesting to overcome the global impact of neglected tropical diseases. Third who report on neglected tropical diseases. Geneva: Document production services, 2015.

ZERBINI, A. M.; CHERNICHARO, C. A. L.; VIANA, E. M.. Estudo da remoção de ovos de helmintos e indicadores bacterianos em um sistema de tratamento de esgoto doméstico por reator anaeróbico e aplicação superficial no solo. In: CONGRESSO BRASILEIRO DE ENGENHARIA SANITÁRIA E AMBIENTAL, 20. Anais. Rio de Janeiro: ABES, 1999.

A CBPC - Companhia Brasileira de Produção Científica (CNPJ: 11.221.422/0001-03) detém os direitos materiais desta publicação. Os direitos referem-se à publicação do trabalho em qualquer parte do mundo, incluindo os direitos às renovações, expansões e disseminações da contribuição, bem como outros direitos subsidiários. Todos os trabalhos publicados eletronicamente poderão posteriormente ser publicados em coletâneas impressas sob coordenação da Sustenere Publishing, da Companhia Brasileira de Produção Científica e seus parceiros autorizados. Os (as) autores (as) preservam os direitos autorais, mas não têm permissão para a publicação da contribuição em outro meio, impresso ou digital, em português ou em tradução. 